\title{
DCLK1 is correlated with MET and ERK5 expression, and associated with prognosis in malignant pleural mesothelioma
}

\author{
HUI WANG ${ }^{1-3^{*}}$, YU-YUAN DAI ${ }^{2 *}$, WEN-QIAN ZHANG ${ }^{2,4}$, PING-CHIH HSU ${ }^{2,5}$, YI-LIN YANG ${ }^{2}$, \\ YU-CHENG WANG ${ }^{2}$, GERALDINE CHAN ${ }^{2}$, ALFRED AU ${ }^{6}$, ZHI-DONG XU ${ }^{2}$, \\ SHU-JUAN JIANG ${ }^{1 * *}$, WEI WANG ${ }^{3 * *}$, DAVID M. JABLONS ${ }^{2}$ and LIANG YOU ${ }^{2}$ \\ ${ }^{1}$ Department of Pulmonary Medicine, Affiliated Shandong Provincial Hospital, Shandong University, \\ Shandong, P.R. China; ${ }^{2}$ Thoracic Oncology Laboratory, Department of Surgery, Comprehensive Cancer Center, \\ University of California, San Francisco, CA 94143, USA; ${ }^{3}$ Department of Respiratory Medicine,
}

The Second Hospital of Shandong University, Shandong; ${ }^{4}$ Department of Thoracic Surgery, Beijing Chao-Yang Hospital, Affiliated with Capital University of Medical Science, Beijing, P.R. China; ${ }^{5}$ Department of Thoracic Medicine, Chang Gung Memorial Hospital, Linkou, Taoyuan 333, Taiwan, R.O.C.; ${ }^{6}$ Division of Diagnostic Pathology, Helen Diller Family Comprehensive Cancer Center, University of California, San Francisco, CA 94143, USA

Received January 30, 2017; Accepted March 20, 2017

DOI: $10.3892 /$ ijo.2017.4021

\begin{abstract}
Malignant pleural mesothelioma (MPM) is an aggressive cancer for which more effective treatments are needed. In this study, strong to moderate staining of MET and ERK5 was detected in 67.1 and $48 \%$ of the analyzed 73 human mesothelioma tumors, and significant correlation of MET and ERK5 expression was identified $(\mathrm{P}<0.05)$. We evaluated the doublecortin-like kinase 1 (DCLK1) expression in human mesothelioma tumors. Our results showed that $50.7 \%$ of the immunohistochemistry analyzed human mesothelioma tumors have strong to moderate staining of DCLK1, and its expression is significantly correlated with MET or ERK5 expression $(\mathrm{P}<0.05)$. Also, the upregulation of DCLK1 is correlated with poor prognosis in MPM patients $(\mathrm{P}=0.0235)$. To investigate whether DCLK1 is downstream of MET/ERK5 signaling in human mesothelioma, the effect of DCLK1 expression was analyzed after treatments with either the MET inhibitor XL184 or the ERK5 inhibitor XMD8-92 in human mesothelioma cell lines. Our results showed that the MET inhibitor XL184 reduced the expression of phospho-ERK5 and DCLK1 expres-
\end{abstract}

Correspondence to: Dr Liang You, Department of Surgery, Helen Diller Family Comprehensive Cancer Center, University of California, 2340 Sutter Street, N-221, San Francisco, CA 94115, USA

E-mail: liang.you@ucsf.edu

Dr Shu-Juan Jiang, Department of Pulmonary Medicine, Affiliated Shandong Provincial Hospital, Shandong University, Shandong 250021, P.R. China

E-mail: jnjsj@sina.com

${ }^{*, * *}$ Contributed equally

Key words: mesothelioma, MET, ERK5, doublecortin-like kinase 1, therapeutic target sion in human mesothelioma cell lines. In addition, the ERK5 inhibitor XMD8-92 reduced the expression of phospho-ERK5 and DCLK1 expression in human mesothelioma cell lines. Furthermore, XML184 and XMD8-92 treatment impaired invasion and tumor sphere formation ability of H290 mesothelioma cells. These results suggest that DCLK1 is regulated by MET/ERK5 signaling in human mesothelioma, and the MET/ ERK5/DCLK1 signaling cascade could be further developed into a promising therapeutic target against mesothelioma.

\section{Introduction}

Malignant pleural mesothelioma (mesothelioma) is an aggressive form of cancer that originates in the mesothelial cells of the pleura of the lung and is closely associated with asbestos exposure (1). Mesothelioma incidence has increased over the last several decades with deaths approximately 43,000 worldwide annually; furthermore, decline is not expected by 2020 (2). Combined treatment with surgery and chemotherapy has improved survival and quality of life for mesothelioma patients; however, most patients survive <12-18 months (3) and long-term survival is dismal (4). Therefore, more effective treatments and early detection strategies for mesothelioma patients are urgently needed.

Receptor tyrosine kinases (RTKs) have a pivotal role in tumor growth and metastasis, and RTKs have been associated with controlling the signaling cascades that result in cell transformation, cell proliferation, and invasion of the transformed cells (5). MET protein, encoded by MET proto-oncogene, is an RTK and a hepatocyte growth factor (HGF) receptor (6). MET is responsible for the modulation of cell growth and is activated in a number of human mesothelioma cell lines and tissues $(7,8)$. Previous studies have demonstrated that HGF induced mesothelioma cell proliferation through activation of PI3K/ERK5/Fra-1 pathway and HGF has also been shown to phosphorylate ERK5 in human mesothelioma cells (9). ERK5, 
a mitogen-activated protein kinase (MAPK), is activated upon a double phosphorylation by the unique MAPK-ERK kinase 5 (MEK5). The MEK5/ERK5 pathway is essential for blood vessel and cardiac development (10). Moreover, the MEK5/ERK5 pathway is important in regulating the proliferation and survival of endothelial cells $(11,12)$ and mesothelioma cells (13).

Doublecortin-like kinase 1 (DCLK1) belongs to the family of calmodulin-dependent kinases and binds to microtubules. It is a marker for tuft cells in the small intestine and pancreas (14-16). DCLK1 is classified as a pancreatic cancer stem-cell marker and its expression is also upregulated in pancreatic ductal adenocarcinoma $(14,17)$. It has been suggested that DCLK1 marks the tumor-initiating cells in numerous tumor types (18-20). Moreover, DCLK1 is also known to act as a regulator for several known oncogenes such as KRAS, NOTCH1 and c-Myc $(17,21,22)$.

Although DCLK1 has been linked to various cancers, little is known about its role in the growth of human mesothelioma. Furthermore, the relationship between MET, ERK5, and DCLK1 in human mesothelioma is unknown. In this study, we sought to evaluate the efficacy of MET, ERK5, and DCLK1 as possible biomarkers and potential targets for therapeutic development for human mesothelioma.

\section{Materials and methods}

Reagents. Monoclonal rabbit anti-human MET [EP1454Y], polyclonal rabbit anti-human MET (phospho Y1230 + Y1234 + Y1235) and polyclonal rabbit anti-human DCLK1 were purchased from Abcam, Inc. (Cambridge, MA,USA). Polyclonal rabbit anti-human ERK5 and polyclonal rabbit anti-human phospho-ERK5 (Thr218/Tyr220) were purchased from Cell Signaling, Inc. (Danvers, MA, USA). Cabozantinib (XL184) and XMD8-92 were purchased from Selleck Chemicals LLC (Houston, TX, USA).

Cell lines and cell culture. Human mesothelioma cell lines 211H, H2052, and H28 were purchased from American Type Culture Collections (ATCC, Manassas, VA, USA). H290 and MS-1 were purchased from NIH (Frederick, MD, USA). H513 and human normal mesothelial cell line LP9 were purchased from the Cell Culture Core Facility at Harvard University (Boston, MA, USA). The mesothelioma cell lines were maintained in RPMI-1640 medium supplemented with $10 \%(\mathrm{v} / \mathrm{v})$ heat-inactivated FBS, penicillin $(100 \mathrm{IU} / \mathrm{ml})$ and streptomycin $(100 \mu \mathrm{g} / \mathrm{ml})$. LP9 was maintained in medium consisting of a 1:1 composition of M199 and M106 medium (Life Technologies) supplemented with $15 \%(\mathrm{v} / \mathrm{v})$ newborn calf serum (Fisher Scientific/Hyclone), $10 \mathrm{ng} / \mathrm{ml}$ EGF and $0.4 \mu \mathrm{g} / \mathrm{ml}$ hydrocortisone, penicillin $(100 \mathrm{IU} / \mathrm{ml})$, and streptomycin $(100 \mu \mathrm{g} / \mathrm{ml})$.

Tissue samples and immunohistochemistry. Fresh mesothelioma and adjacent normal pleural tissues were obtained from patients with malignant plural mesothelioma who underwent surgical resection of the primary tumor at University of California, San Francisco Medical Center from July 1997 to December 2008. Primary human mesothelioma samples from 73 patients were fixed in formalin and embedded in paraffin in $4-\mu \mathrm{m}$ tissue microarray sections. In eight of these patients, a small amount of normal pleural tissue had been obtained simultaneously to serve as controls. We only have complete information of 45 of the patients. For the other 28 patients, the information is incomplete. The average age of these 45 patients is 68.13 years, and the median age is 69 years. The mean following up period for these patients is 2 years based on their registered last visit date. The end-point record relies on the notification of the deaths of these registered patients to the medical center and the obituary information. All human tissue samples were obtained and analyzed in accordance with procedures approved by the institutional review board of the University of California, San Francisco (IRB H8714-22 942-01), and written informed consent was obtained from all subjects. All the methods were carried out in accordance with the approved guidelines.

The sections were immunostained as previously described (23). The sections and mesothelioma cell lines H290, H513, H28, 211H, MS-1 and H2052 and mesothelial cell line LP9 were immunostained stained with the properly diluted antibodies: anti-MET (ab51067) at 1:400; anti-ERK at 1:100; anti-DCLK1 (ab31704) at 1:300.

The following scoring system was used: -, no stain; + , weak staining ( $\geq 10 \%$ stained cellularity considered as positive); ++ , moderate staining ( $\geq 30 \%$ stained cellularity considered as positive); +++ , strong staining ( $\geq 50 \%$ stained cellularity considered as positive). The scoring was done under a low power objective lens (x10) with a Zeiss Axioscop 2 microscope (Carl Zeiss Inc., Germany). Images were taken under a x10 or x20 or x40 objective lens.

Cell viability assay. Cells were cultured in a 96-well plate and treated with different doses of XL184 and XMD8-92 (XL184: $0,0.001,0.003,0.01,0.03,0.1,0.3,1,3,10$ and $30 \mu \mathrm{M}$; XMD8-92: $0,0.003,0.01,0.03,0.1,0.3,1,3,10,30$ and $100 \mu \mathrm{M})$. After $48 \mathrm{~h}$ of incubation, cells were lysed and luminescent signaling was generated by a CellTiter-Glo Luminescent Cell Viability assay reagent (Promega). Luminescent signaling was measured on the GloMax-96 Microplate Luminometer. Proportional cell viability was analyzed with GraphPad Prism 6 software (GraphPad Software, Inc., La Jolla, CA, USA), which was used to calculate dose-response curves and $\mathrm{IC}_{50}$.

Western blot analysis. Total protein was extracted from cell lines using M-PER Mammalian Protein Extraction reagent (Thermo Fisher Scientific, Waltham, MA, USA) supplied with Complete Protease Inhibitor Cocktails (Roche, Lewes, UK), according to the manufacturer's protocols. The protein concentrations were measured with the Pierce BCA Protein assay kit (Thermo Fisher Scientific). A total of $30 \mu \mathrm{g}$ of proteins were run on 4-20\% gradient SDS-polyacrylamide gels (Bio-Rad Laboratories, Inc., Hercules, CA, USA) and transferred to Immobilon-P nitrocellulose membranes (Millipore, Bellerica, MA, USA). The membranes were blocked in 5\% BSA and then probed with the primary antibodies overnight at $4^{\circ} \mathrm{C}$. The membranes were incubated with appropriate secondary antibodies, either peroxidase-conjugated anti-mouse or anti-rabbit (Santa Cruz Biotechnology, Santa Cruz, CA, USA). GAPDH was used as a loading control. Then the antigen-antibody complexes were detected by using an ECL blotting analysis system (Amersham Pharmacia Biotech, Piscataway, NJ, USA). 
Table I. Positive and negative number and ratio of MET, ERK5, and DCLK1 in normal pleural samples.

\begin{tabular}{lllll}
\hline & $\begin{array}{c}\text { Number } \\
\text { (ratio) }\end{array}$ & \multicolumn{1}{c}{$\begin{array}{c}\text { Number } \\
\text { (ratio) }\end{array}$} & $\begin{array}{c}\text { ++ Number } \\
\text { (ratio) }\end{array}$ & $\begin{array}{c}\text { +++ Number } \\
\text { (ratio) }\end{array}$ \\
\hline MET & $4(50.0 \%)$ & $3(37.5 \%)$ & $1(12.5 \%)$ & $0(0 \%)$ \\
ERK5 & $5(62.5 \%)$ & $3(37.5 \%)$ & $0(0 \%)$ & $0(0 \%)$ \\
DCLK1 & $6(75 \%)$ & $2(25 \%)$ & $0(0 \%)$ & $0(0 \%)$ \\
\hline
\end{tabular}

Quantitative real-time PCR. Total RNA was extracted from cells using the RNeasy Mini kit (Qiagen, Valencia, CA, USA). The cDNA was transcribed from $1 \mu \mathrm{g}$ of total RNA using iScript cDNA Synthesis kits (Bio-Rad), according to the manufacturer's protocol. The cDNA was used as the template for real-time PCR detection using TaqMan Technology on an Applied Biosystems 7900HT sequence detection system (Applied Biosystems, Foster City, CA, USA). Expression of MET, ERK5, and DCLK1 genes, and endogenous control gene $\beta$-glucuronidase (GUSB) were detected by using probes commercially (Applied Biosystems) and analyzed using Relative Quantification Software SDS 2.4 (Applied Biosystems). The relative mRNA expression level of DCLK1 in each sample was calculated using the comparative expression level $2^{-\Delta \Delta \mathrm{Ct}}$ method. All experiments were carried out in triplicate for each data point.

Transwell invasion assay. The Transwell invasion assay was performed in a 6-well plate Transwell system (Corning Inc., NY, USA). The Transwell inserts were coated with $300 \mu 1$ Matrigel and incubated at $37^{\circ} \mathrm{C}$ for half an hour. Cells $\left(3 \times 10^{5}\right)$ of $\mathrm{H} 290$ and $\mathrm{H} 2052$ were harvested and resuspended in serum-free medium supplemented with $1.0 \mu \mathrm{M}$ XL184, $1.0 \mu \mathrm{M}$ XMD8-92 or DMSO (0.1\%) to the upper chamber of the Transwell. The lower chamber was infused with $2.6 \mathrm{ml}$ complete growth medium (10\% FBS). The Transwell was incubated at $37^{\circ} \mathrm{C}$ for $20 \mathrm{~h}$, and then the gel and cells in the upper chamber were removed. After formalin fixation, the membrane was stained by crystal violet (Sigma, St. Louis, MO, USA) for $20 \mathrm{~min}$. Phase contrast images were taken and the cells on the lower side of the membrane were counted in six random visual fields under a 20x objective lens.

Tumorsphere assays. Number $\left(1 \times 10^{3}\right)$ of $\mathrm{H} 290$ single-cell

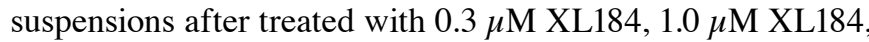
$0.3 \mu \mathrm{M}$ XMD8-92, $1.0 \mu \mathrm{M}$ XMD8-92 or DMSO (0.1\%) for $48 \mathrm{~h}$ were plated in 24-well ultra-low attachment plates (Corning Inc.) in StemPro MSC SFM Basal Medium CTS + StemPro MSC SFM Supplement CTS (Life Technologies, Grand Island, NY, USA), $2 \mathrm{nM}$ L-glutamine, and penicillin $(100 \mathrm{IU} / \mathrm{ml})$. Tumorspheres were cultured for 7 days. Tumorspheres formed in non-adherent cultures were counted under a 10x objective lens. The cut-off size for the spheres counted is $60 \mu \mathrm{m}$.

Statistical analysis. Data are expressed as mean \pm standard deviation (SD) from three independent experiments. The Chi-square independence test was used to compare IHC results
Table II. Positive and negative number and ratio of MET, ERK5, and DCLK1 in mesothelioma samples.

\begin{tabular}{lcccc}
\hline & $\begin{array}{c}\text { Number } \\
\text { (ratio) }\end{array}$ & $\begin{array}{c}\text { Number } \\
\text { (ratio) }\end{array}$ & $\begin{array}{c}\text { ++ Number } \\
\text { (ratio) }\end{array}$ & $\begin{array}{c}\text { +++ Number } \\
\text { (ratio) }\end{array}$ \\
\hline MET & $6(8.2 \%)$ & $18(24.7 \%)$ & $39(53.4 \%)$ & $10(13.7 \%)$ \\
ERK5 & $14(19.2 \%)$ & $24(32.8 \%)$ & $28(38.4 \%)$ & $7(9.6 \%)$ \\
DCLK1 & $14(19.2 \%)$ & $22(30.1 \%)$ & $26(35.6 \%)$ & $11(15.1 \%)$ \\
\hline
\end{tabular}

between the staining intensity of MET, ERK5, and DCLK1 in the same mesothelioma tumors. The other statistical analyses were performed using the GraphPad Prism (Version 6.0; GraphPad Software, San Diego, CA, USA). Student's t-test was used for comparison between two groups. One-way ANOVA followed by Scheffe multiple comparisons were used to compare the differences among multiple groups. Survival analysis in these 45 patients was performed by Kaplan-Meier analysis with GraphPad Prism (Version 6.0; GraphPad software). A significant difference was considered when the P-value from a two-tailed test was $<0.05$.

\section{Results}

MET, ERK5, and DCLK1 are overexpressed in human mesothelioma tumors. To investigate MET, ERK5, and DCLK1 expression in human mesothelioma cells, primary human mesothelioma tissue samples from 73 patients were analyzed using immunohistochemistry. Tables I and II indicated the positive or negative results for MET, ERK5, and DCLK1 staining in tissue microarray sections of human mesothelioma and normal pleural samples.

MET was stained in the cytoplasm of mesothelioma samples (Fig. 1A). In the eight normal pleural tissue samples, $50.0 \%$ was negative, $37.5 \%$ was weak, $12.5 \%$ was moderate, and none of the samples had strong MET staining (Table I). In the 73 human mesothelioma samples, $8.2 \%$ was negative, $24.7 \%$ was weak, $53.4 \%$ was moderate, and $13.7 \%$ had strong MET staining (Table II). Our results showed that moderate to strong staining for MET was detected in $67.1 \%$ of the analyzed mesothelioma tumor samples but in only $12.5 \%$ of the normal pleural tissues. The results of MET staining in mesothelioma cell lines H290, H513, H28, 211H, MS-1, and H2052 and normal mesothelial cell line LP9 are shown in Fig. 1B. Four of the tested mesothelioma cell lines H290, H513, H28 and $211 \mathrm{H}$ showed strong positive staining for MET, whereas MS-1, H2052 and normal mesothelial cell line LP9 showed negative staining for MET, indicating a lack of expression (Fig. 1B).

ERK5 was stained in the cytoplasm or nuclei of mesothelioma samples (Fig. 2A). In the eight normal pleural tissue samples, $62.5 \%$ was negative, $37.5 \%$ was weak, and none of the samples had moderate or strong ERK5 staining (Table I). In the 73 human mesothelioma samples, $19.2 \%$ was negative, $32.8 \%$ was weak, $38.4 \%$ was moderate, and $9.6 \%$ had strong ERK5 staining (Table II). Our results showed that moderate to strong staining for ERK5 was detected in $48 \%$ of the analyzed mesothelioma tumor samples but not in the normal pleural tissues. The results of ERK5 staining in mesothelioma cell 


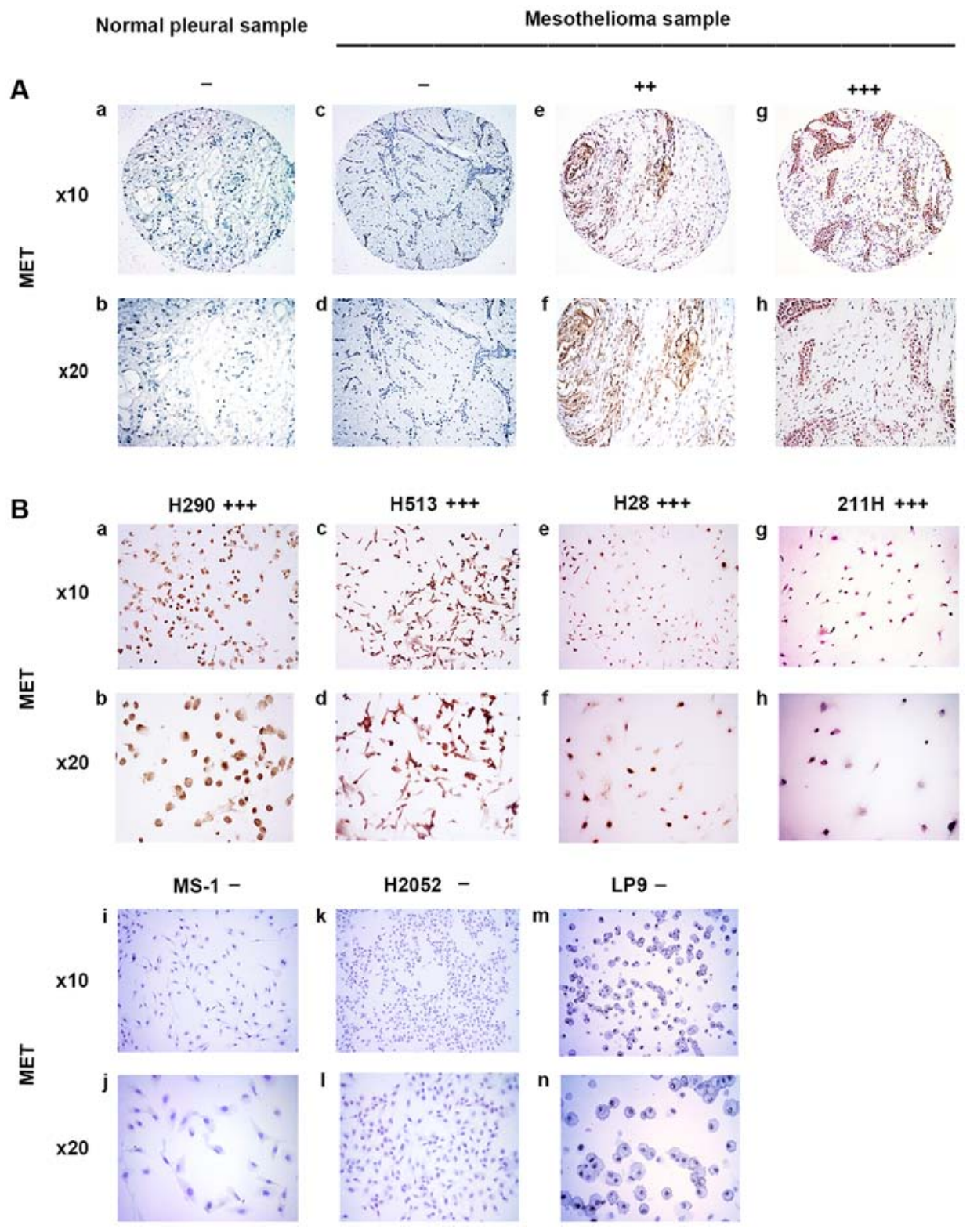

Figure 1. Immunohistochemistry of MET in normal pleural and mesothelioma samples. (A) a and b, normal pleura sample. c-h, mesothelioma samples. c and d, negative. e and f, moderate stain. g and h, strong stain. (B) Mesothelioma cell lines. a and b, H290, strong stain. $\mathrm{c}$ and d, H513, strong stain. e and f, H28, strong stain. $g$ and $\mathrm{h}, 211 \mathrm{H}$, strong stain. i and j, MS-1, negative. $\mathrm{k}$ and 1, H2052, negative. $\mathrm{m}$ and $\mathrm{n}$, normal mesothelial cell line LP9, negative.

Table III. Chi-square test for association analysis of MET and ERK5 expression in mesothelioma tumors $(\mathrm{P}=0.00000212$; $\mathrm{P}<0.05$, Chi-square).

\begin{tabular}{lcc}
\hline & $\begin{array}{c}\text { ERK5 }(-/+)(\%) \\
(\mathrm{n} / \text { total })\end{array}$ & $\begin{array}{c}\text { ERK5 }(++/+++)(\%) \\
(\mathrm{n} / \text { total })\end{array}$ \\
\hline ERK5 (-/+) & $30.1(22 / 73)$ & $21.9(16 / 73)$ \\
ERK5 $(++/+++)$ & $2.8(2 / 73)$ & $45.2(33 / 73)$ \\
\hline
\end{tabular}

lines H290, H513, H28, 211H, MS-1, and H2052 and normal mesothelial cell line LP9 are shown in Fig. 2B. The H290 cell line also showed strong positive staining for ERK5, whereas the H513 and H28 cell lines showed moderately positive staining for ERK5. Cell lines 211H, MS-1, H2052 and normal
Table IV. Chi-square test for association analysis of MET and DCLK1 expression in mesothelioma tumors $(\mathrm{P}=0.00000495$; $\mathrm{P}<0.05$, Chi-square).

\begin{tabular}{lcc}
\hline & $\begin{array}{c}\text { ERK5 (-/+) }(\%) \\
(\mathrm{n} / \text { total })\end{array}$ & $\begin{array}{c}\text { ERK5 }(++/+++)(\%) \\
(\mathrm{n} / \text { total })\end{array}$ \\
\hline DCLK1 (-/+) & $28.8(21 / 73)$ & $20.5(15 / 73)$ \\
DCLK1 $(++/+++)$ & $4.1(3 / 73)$ & $46.6(34 / 73)$ \\
\hline
\end{tabular}

mesothelial cell line LP9 showed negative staining for ERK5 (Fig. 2B).

DCLK1 was stained in the nuclei of normal pleural samples and mesothelioma samples (Fig. 3A). In the eight normal pleural tissue samples, $75 \%$ was negative, $25 \%$ was weak, and 

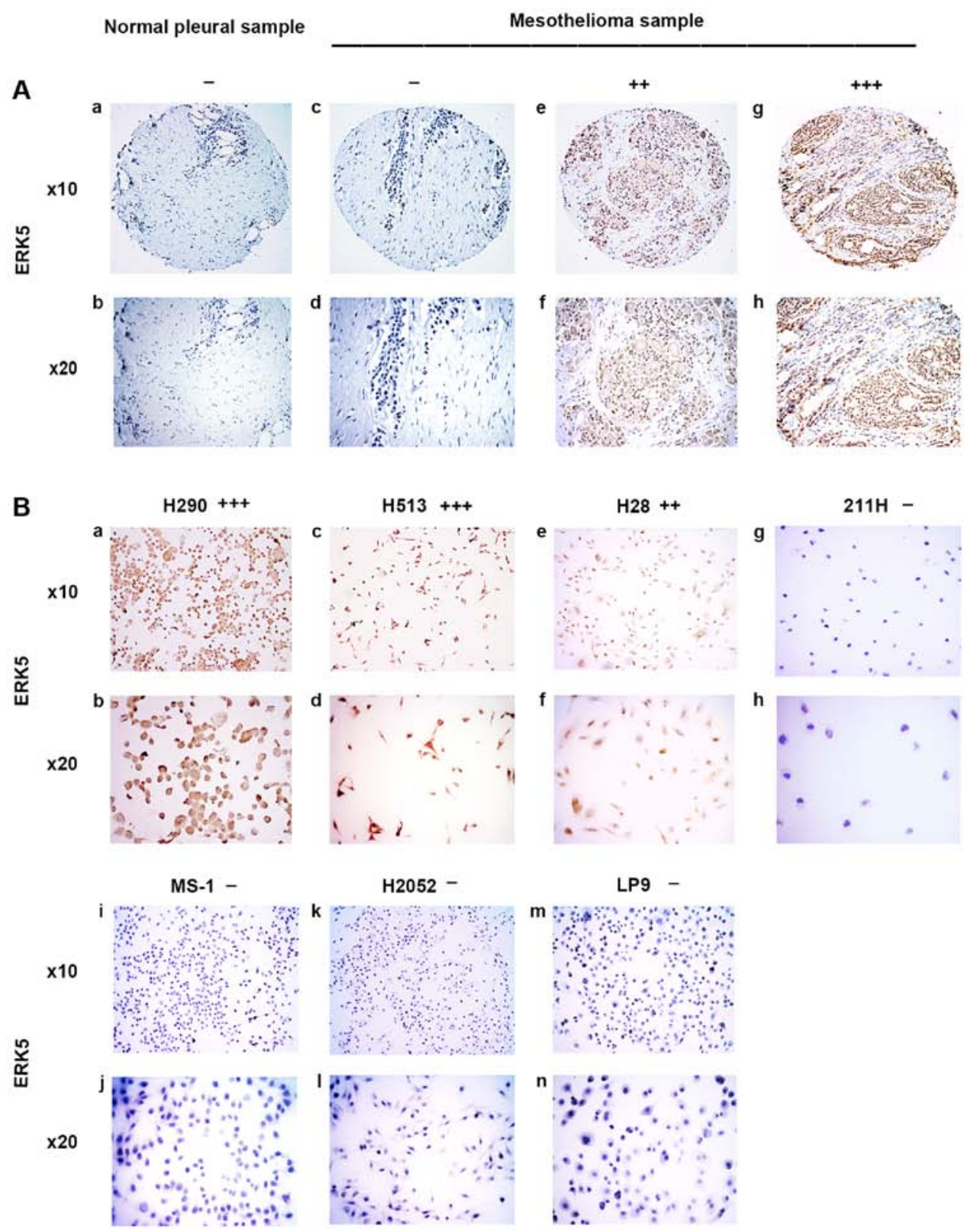

Figure 2. Immunohistochemistry of ERK5 in normal pleural and mesothelioma samples. (A) a and b, normal pleura sample. c-h, mesothelioma samples. $\mathrm{c}$ and d, negative. e and f, moderate stain. $g$ and h, strong stain. (B) Mesothelioma cell lines. a and b, H290, strong stain. c and d, H513, moderate stain. e and f, H28, moderate stain. $g$ and h, 211H, negative; i and j, MS-1, negative. $\mathrm{k}$ and 1, H2052, negative. m and n, normal mesothelial cell line LP9, negative.

Table V. Chi-square test for association analysis of ERK5 and DCLK1 expression in mesothelioma tumors $(\mathrm{P}=0.00001429$; $\mathrm{P}<0.05$, Chi-square).

\begin{tabular}{lcc}
\hline & $\begin{array}{c}\text { ERK5 (-/+) }(\%) \\
(\mathrm{n} / \text { total })\end{array}$ & $\begin{array}{c}\text { ERK5 (++/+++) }(\%) \\
(\mathrm{n} / \text { total })\end{array}$ \\
\hline DCLK1 (-/+) & $38.3(28 / 73)$ & $11(8 / 73)$ \\
DCLK1 $(++/+++)$ & $13.7(10 / 73)$ & $37(27 / 73)$ \\
\hline
\end{tabular}

none of the samples had moderate or strong DCLK1 staining (Table I). In the 73 human mesothelioma samples, 19.2\% was negative, $30.1 \%$ was weak, $35.6 \%$ was moderate, and $15.1 \%$ had strong DCLK1 staining (Table II). Our results showed that moderate to strong staining for DCLK1 was detected in $50.7 \%$ of the analyzed mesothelioma tumor samples but not in the normal pleural tissues. The results of DCLK1 staining in mesothelioma cell lines H290, H513, H28, 211H, MS-1, H2052 and normal mesothelial cell line LP9 are shown in Fig. 3B. H290 and H28 cell lines showed strong positive staining for DCLK1 and the H513 cell line showed moderate staining for DCLK1. The cell lines 211H, MS-1, H2052, and normal mesothelial cell line LP9 were all negative for DCLK-1 (Fig. 3B).

Our analysis also showed that, in $38.4 \%$ of the mesothelioma tumor samples, moderate to strong expression of all three proteins was detected $(n=28)$ (Fig. 4A and Tables I and II). Statistical analysis revealed a significant association between MET, ERK5, and DCLK1 expression in these mesothelioma samples $(\mathrm{P}<0.05$, Chi-square test $)$ (Tables III-V). We analyzed the IHC staining score of MET, ERK5, and DCLK1 


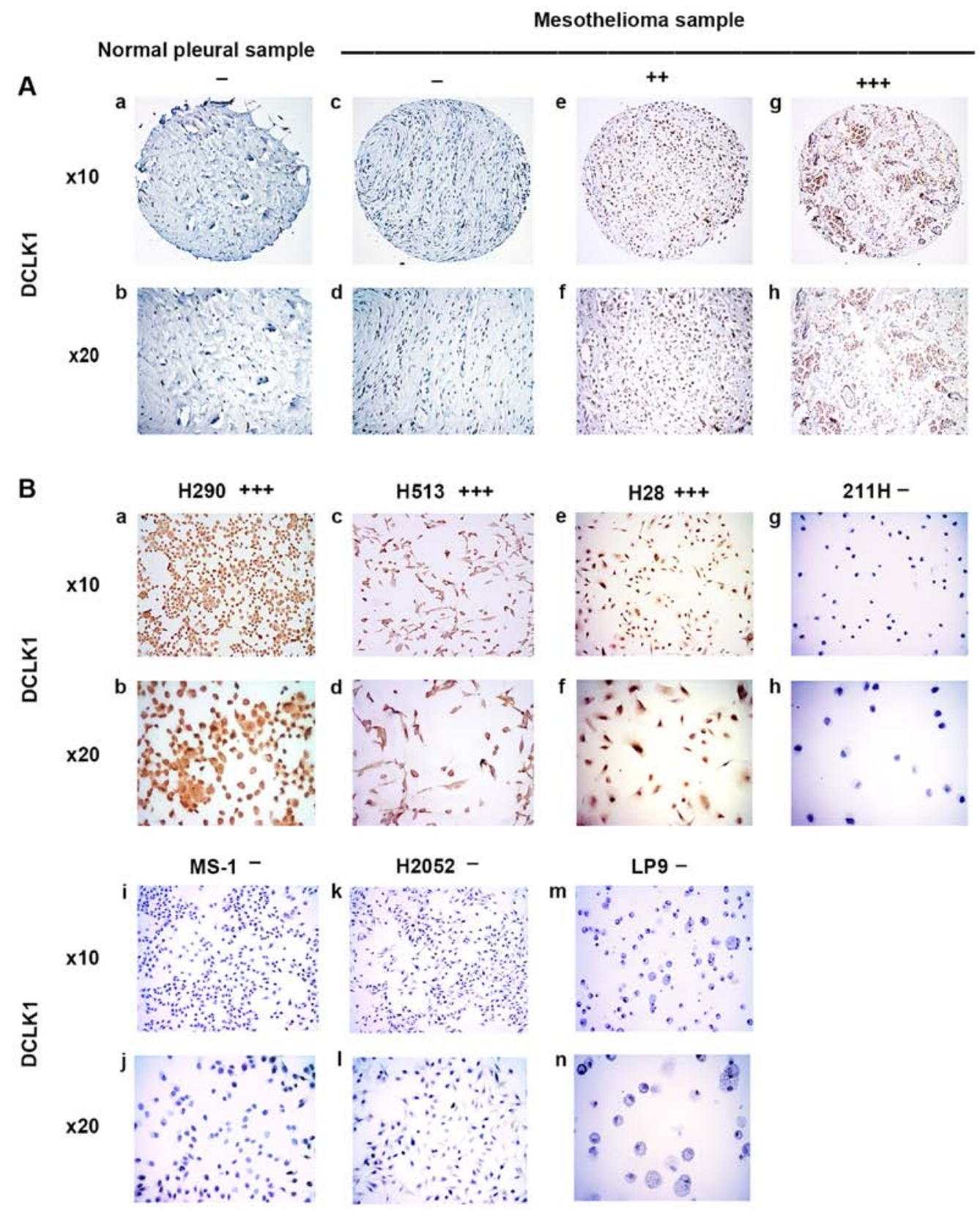

Figure 3. Immunohistochemistry of DCLK1 in normal pleural and mesothelioma samples. (A) a and b, normal pleura sample. c-h, mesothelioma samples. $\mathrm{c}$ and d, negative. e and f, moderate stain. $\mathrm{g}$ and $\mathrm{h}$, strong stain. (B) Mesothelioma cell lines. a and b, H290, strong stain. $\mathrm{c}$ and d, H513, moderate stain. e and $\mathrm{f}$, $\mathrm{H} 28$, strong stain. $\mathrm{g}$ and $\mathrm{h}, 211 \mathrm{H}$, negative. $\mathrm{i}$ and $\mathrm{j}$, MS-1, negative. $\mathrm{k}$ and 1, H2052, negative. $\mathrm{m}$ and $\mathrm{n}$, normal mesothelial cell line LP9, negative.

Table VI. Results of immunohistochemistry staining of DCLK1 in normal pleural and mesothelioma samples.

\begin{tabular}{lcccccccr}
\hline & \multicolumn{9}{c}{ Level of DCLK1 expression } & & \\
\cline { 2 - 6 } Histologic classification & - & + & ++ & Total & P-value \\
\hline Normal pleural & $6(75 \%)$ & $2(25 \%)$ & 0 & $(0 \%)$ & 0 & $(0 \%)$ & 8 & \\
Mesothelioma & $14(19.2 \%)$ & $22(30.1 \%)$ & $26(35.6 \%)$ & $11(15.1 \%)$ & 73 & 0.000986 \\
\hline
\end{tabular}

of mesothelioma samples and normal pleural tissues obtained from 8 patients (Fig. 4B-D). Statistical analysis indicated a significant higher expression of MET, ERK5 and DCLK1 in mesothelioma samples compared to their expressions in normal pleural tissues obtained from the sample 8 patients.
DCLK1 upregulation correlates with poor prognosis in mesothelioma. DCLK1 expression was significantly higher in MPM patients' tissues than normal pleural tissues (Table VI) $(\mathrm{P}=0.000409)$, suggesting a possible oncogenic role of DCLK1 in MPM. Analyzing the associations between DCLK1 
A

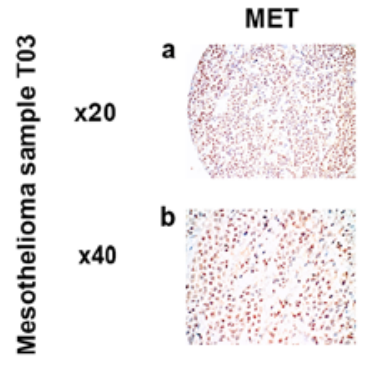

ERK5
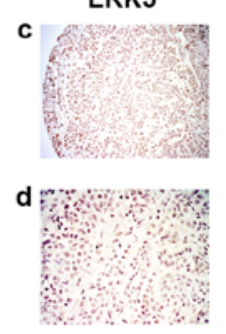

DCLK1
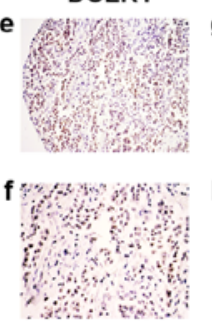
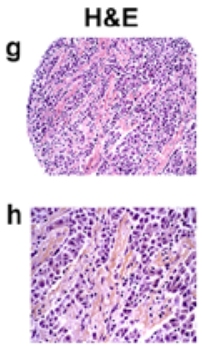

B

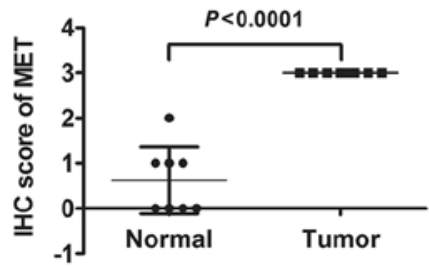

C

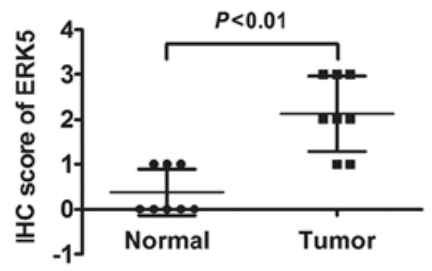

D

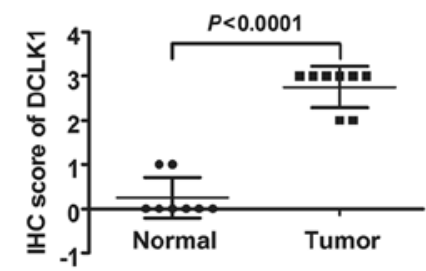

E

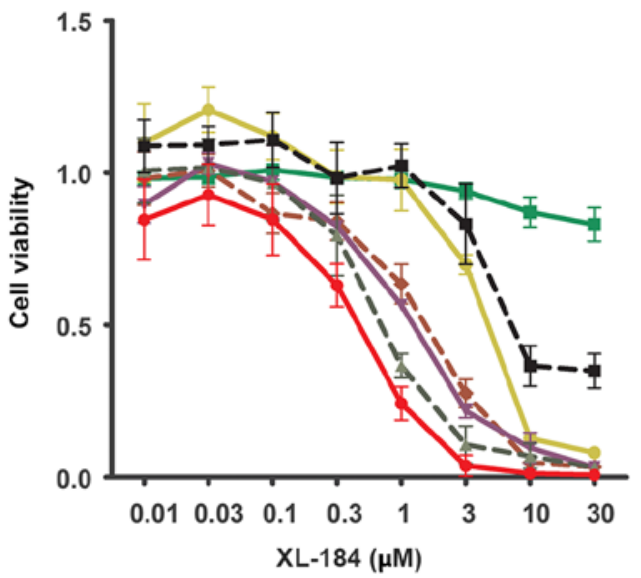

$\mathbf{F}$

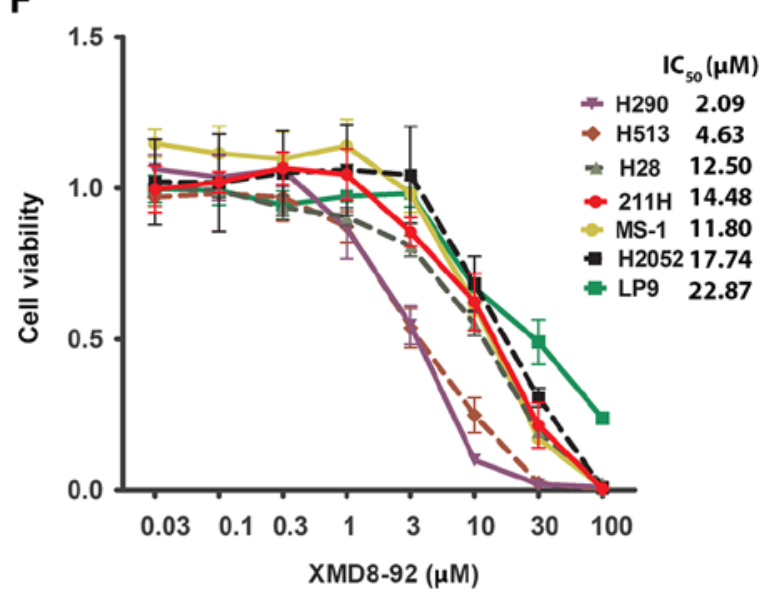

Figure 4. Immunohistochemistry of MET, ERK5, and DCLK1, and H\&E staining in one mesothelioma sample and cell viability assay of XL184 and XMD8-92. (A) Immunohistochemistry of MET (a and b), ERK5 (c and d) and DCLK1 (e and f) and H\&E (g and h) staining in T03 mesothelioma sample. (B) Scatter plot of IHC score of MET from mesothelioma tissues and normal tissues from 8 patients $(\mathrm{P}<0.0001$, Student's t-test). (C) Scatter plot of IHC score of MET from mesothelioma tissues and normal tissues from 8 patients $(\mathrm{P}<0.001$, Student's t-test). (D) Scatter plot of IHC score of MET from mesothelioma tissues and normal tissues from 8 patients ( $\mathrm{P}<0.0001$, Student's t-test). (E) Cell viability assay of six mesothelioma cell lines (H290, H513, H28, 211H, MS-1 and H2052) and one normal mesothelial cell line LP9 after treatment with the MET inhibitor XL184. (F) Cell viability assay of six mesothelioma cell lines (H290, H513, H28, 211H, MS-1 and H2052) and one normal mesothelial cell line LP9 after treatment with the ERK5 inhibitor XMD8-92.

expression and clinicopathologic characteristics, we did not find significantly correlations between DCLK1 and age, gender, smoke status or TNM stage (Table VII). We further evaluated the correlation between DCLK1 expression and overall survival (OS) in MPM patients using Kaplan-Meier analysis. As shown in Fig. 5, the OS times with high DCLK1 staining (2-3) is significantly shorter than those with low DCLK1 staining (0-1) (24 vs. $21, \mathrm{P}=0.0235)$, which indicated DCLK1 level is a potential indicator of OS survival of MPM patients.

MET and ERK5 inhibitors suppress cell viability of human mesothelioma cells. We tested the effects of MET and ERK5 inhibitors on six mesothelioma cell lines H290, H513, H28, $211 \mathrm{H}, \mathrm{MS}-1$, and $\mathrm{H} 2052$ and on the normal human mesothelial cell line LP9 by treating them with MET inhibitor XL184 and ERK5 inhibitor XMD8-92 at different doses for $48 \mathrm{~h}$. Cell viability was assayed and $\mathrm{IC}_{50}$ of each cell line was calcu- lated based on the dose-response curves (Fig. 4E and $\mathrm{F}$ and Table VIII). A higher dose of XL184 and XMD8-92 resulted in lower viability of the mesothelioma cell lines. The $\mathrm{IC}_{50}$ values indicate different levels of inhibitory effects of XL184 and XMD8-92 among the cell lines and are displayed in Fig. 4B and $\mathrm{C}$, respectively. Importantly, four of the mesothelioma cell lines (H290, H513, H28 and 211H), in which strong positive staining with anti-MET antibody was detected by immunohistochemistry, showed relatively high sensitivity to the MET inhibitor XL184 compared to the cell lines with weak staining of anti-MET. In contrast, XL184 had minimal inhibitory effects on the viability of the normal human mesothelial cell line LP9. Three cell lines (H290, H513 and H28) stained positive with anti-ERK5 antibody, which also showed relative high sensitivity to the ERK5 inhibitor XMD8-92.

MET or ERK5 inhibition causes downregulation of MET/ ERK5/DCLK1 signaling. To assess whether inhibiting MET 


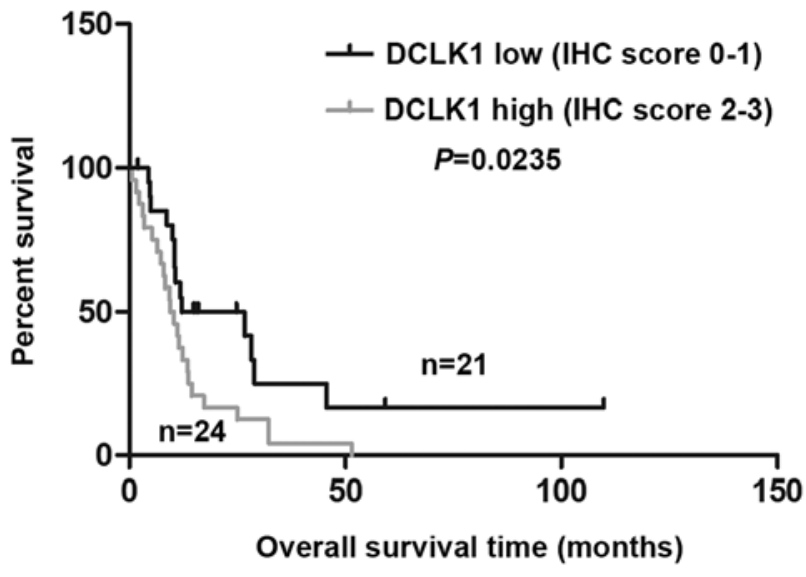

Figure 5. Kaplan-Meier survival curves for patients with MPM. Survival analysis in 45 MPM patients was performed. Patients with high (2-3) DCLK1 IHC staining score had significant shorter survival time than those with low (0-1) DCLK1 IHC staining score ( $\mathrm{P}=0.0235)$.

Table VII. Association between clinicopathological characteristics and DCLK1 protein expression in 45 cases of primary mesothelioma tissues with available clinicopathological information.

\begin{tabular}{lrrrr}
\hline & & \multicolumn{2}{l}{ Level of DCLK1 expression } & \\
\cline { 3 - 4 } Clinical & Total & Low & High & P-value \\
information & & & & \\
\hline Age & & & & \\
$<70$ & 23 & $12(52.2 \%)$ & $11(47.8 \%)$ & 0.449 \\
$\geq 70$ & 22 & $9(40.9 \%)$ & $13(59.1 \%)$ & \\
Gender & & & & \\
Male & 34 & $18(52.9 \%)$ & $16(47.1 \%)$ & 0.926 \\
Female & 11 & $6(54.5 \%)$ & $5(45.5 \%)$ & \\
Smokers & & & & \\
Never & 17 & $8(47.1 \%)$ & $9(51.9 \%)$ & 0.722 \\
Past & 25 & $14(56.0 \%)$ & $11(44.5 \%)$ & \\
Current & 3 & $2(66.7 \%)$ & $1(33.3 \%)$ & \\
TNM stage & & & & \\
I & 6 & $4(66.7 \%)$ & $2(33.3 \%)$ & 0.363 \\
II & 9 & $2(22.2 \%)$ & $7(77.8 \%)$ & \\
III & 12 & $6(50.0 \%)$ & $6(50.0 \%)$ & \\
IV & 5 & $2(40.0 \%)$ & $3(60.0 \%)$ & \\
\hline
\end{tabular}

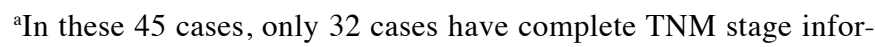
mation. or ERK5 affects MET/ERK5/DCLK1 signaling activity, we analyzed phospho-MET, MET, phospho-ERK5, ERK5 and DCLK1 expression in H290 and H513 cell lines treated with the MET inhibitor XL184 or the ERK5 inhibitor XMD8-92. We found that phosphor-MET, phospho-ERK5 and DCLK1 protein level decreased after treatment with XL184 (Fig. 6A) or XMD8-92 (Fig. 6B) in the mesothelioma cells, as compared to what occurred in cells treated with DMSO. MET and ERK5 protein level was not decreased after the treatments (Fig. 6A and B). Significant decrease in mRNA levels of DCLK1 was detected in both $\mathrm{H} 290$ and H513 cells after XL184 or XMD8-92 treatments analyzed by quantitative real-time PCR (Fig. 7). These results suggest that MET or ERK5 inhibition decreased the expression of phospho-ERK5 and DCLK1 in $\mathrm{H} 290$ and H513 cells. Our proposed schema for MET/ ERK5/DCLK1 signaling in human mesothelioma is shown in Fig. 6C. The use of specific inhibitors, XL184 and XMD8-92, one targeting MET signaling and the other targeting ERK5, decreased the mRNA levels and protein levels of DCLK1 in human mesothelioma cells, suggesting that DCLK1 lies downstream of both MET and ERK5 signaling.

MET or ERK5 inhibition impairs invasion and tumor sphere formation ability of mesothelioma H290 cells. To test the effect of MET or ERK5 inhibition on the invasion ability of mesothelioma cells, a Transwell assay was performed using H290 cells and H2052 (Fig. 8A and B). After $20 \mathrm{~h}$ of $1.0 \mu \mathrm{M}$ XL184, $1.0 \mu \mathrm{M}$ XMD8-92 or $0.1 \%$ DMSO treatment, the number of the $\mathrm{H} 290$ cells that invaded to the lower side of the membrane decreased significantly compared to that in the control group treated with DMSO. However, $20 \mathrm{~h}$ of $1.0 \mu \mathrm{M}$ XMD8-92 treatment did not affect the invasion of the H2052 cells compared to that in the control DMSO group. Twenty hours of $1.0 \mu \mathrm{M}$ XL184 treatment slightly deceased the number of the H2052 cells invaded to the lower side of the membrane compared to that in the control DMSO group. The cell viability of $\mathrm{H} 290$ treated with $1.0 \mu \mathrm{M}$ XL184 and $1.0 \mu \mathrm{M}$ XMD8-92 for $20 \mathrm{~h}$ were $84.9 \pm 1.0$ and $95.2 \pm 1.5 \%$ respectively, compared to cells treated with $0.1 \%$ DMSO. The cell viability of $\mathrm{H} 2052$ was not affected by $1.0 \mu \mathrm{M}$ XL184 and $1.0 \mu \mathrm{M}$ XMD8-92 treatment for $20 \mathrm{~h}$ compared to cells treated with $0.1 \%$ DMSO.

To measure the effect of EMT or ERK5 inhibition on the self-renewal of cancer stem cells in mesothelioma, we used a tumorsphere assay. Under our experimental conditions, H2052 and MS-1 cells could not form compact spheres after 1 -week incubation. Currently, we do not know the reason for this. However, H290 cells nicely formed compact spheres. Tumorsphere formation efficiency decreased significantly in a dose-dependent manner in $\mathrm{H} 290$ after $(0.3$ and $1.0 \mu \mathrm{M})$ XL184 or (0.3 and 1.0 $\mu \mathrm{M})$ XMD8-92 treatment (Fig. $8 \mathrm{C}$ and D).

Table VIII. IC $_{50}$ values of XL184 and XMD8-92 in six mesothelioma cell lines and a normal pleural cell line.

\begin{tabular}{lccrrrrr}
\hline & H290 & H513 & H28 & $211 \mathrm{H}$ & MS-1 & H2052 & LP-9 \\
\hline $\mathrm{IC}_{50}$ values of XL184 $(\mu \mathrm{M})$ & 1.27 & 1.54 & 0.63 & 0.46 & 3.73 & $>3$ \\
$\mathrm{IC}_{50}$ values of XMD8-92 $(\mu \mathrm{M})$ & 2.09 & 4.63 & 12.50 & 14.48 & 11.80 & 17.74 & 22.87 \\
\hline
\end{tabular}



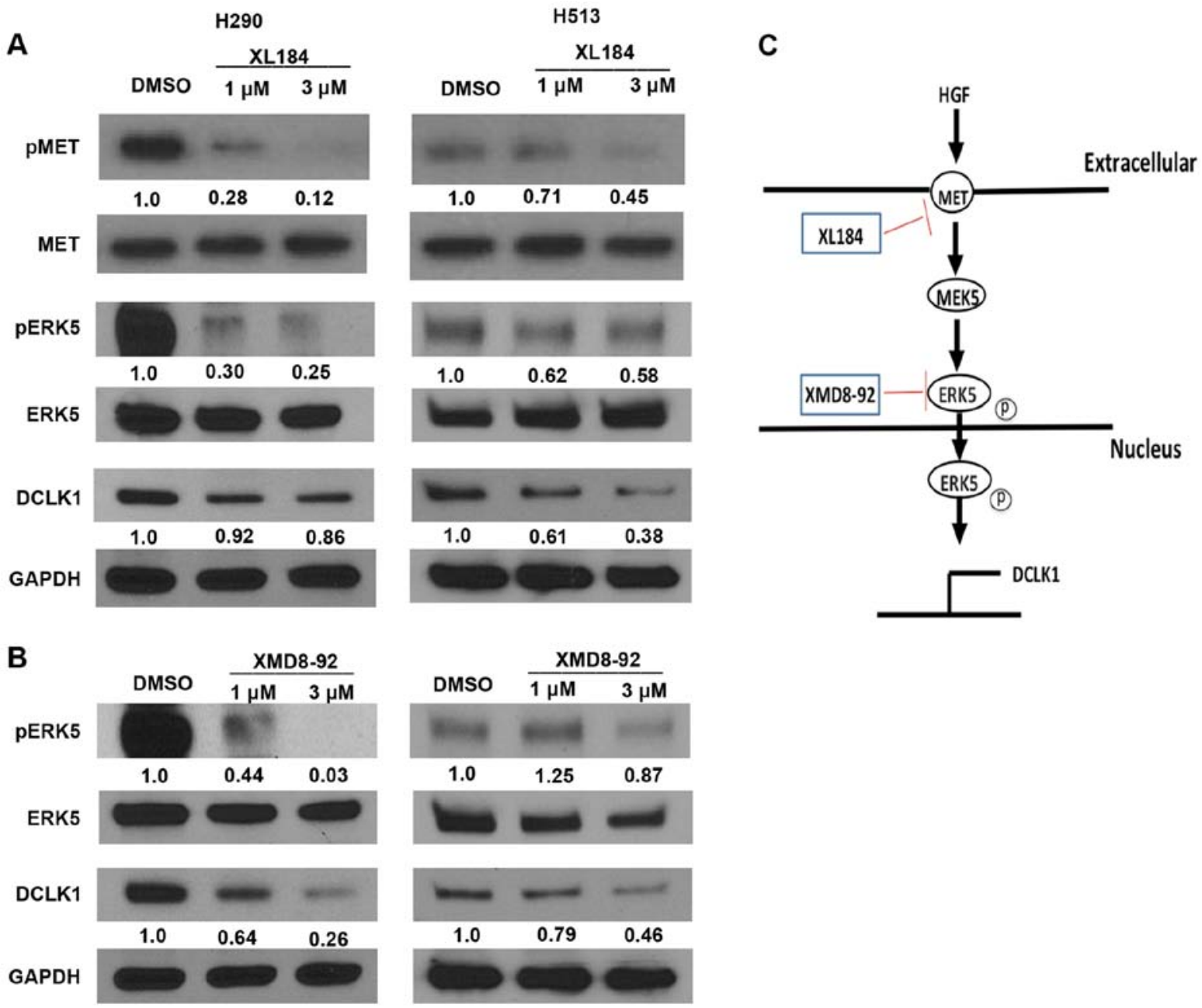

Figure 6. Analysis of MET/ERK5/DCLK1 signaling expression after MET or ERK5 inhibition in mesothelioma cells. (A) Western blot analysis of p-MET/MET ratios, p-ERK5/ERK5 ratios and DCLK1 expression in H290 and H513 cells treated with the MET inhibitor XL184 at 1 or $3 \mu$ M. (B) Western blot analysis of p-ERK5/ERK5 ratios and DCLK1 expression in H290 and H513 cells treated with the ERK5 inhibitor XMD8-92 at 1 or $3 \mu$ M. Band intensity of western blot analysis was measured with ImageJ software. The intensity ratios (pERK5/ERK5; DCLK1/GAPDH) were labeled on the figures. (C) Proposed schema of MET/ERK5/DCLK1 signaling in mesothelioma.

A

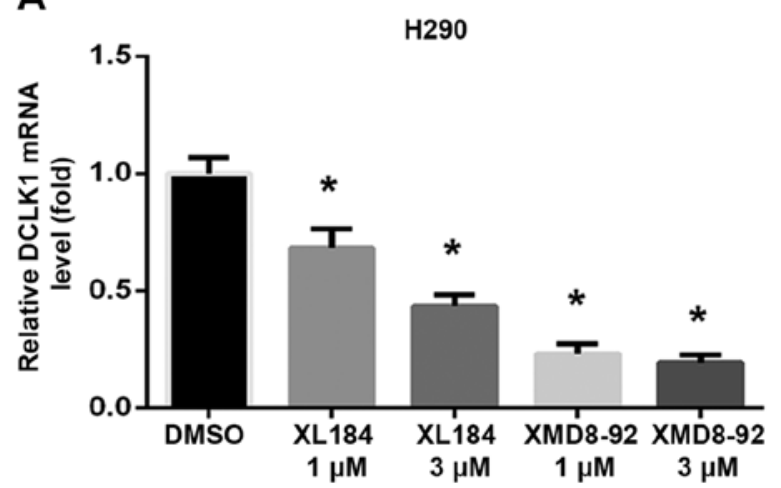

B

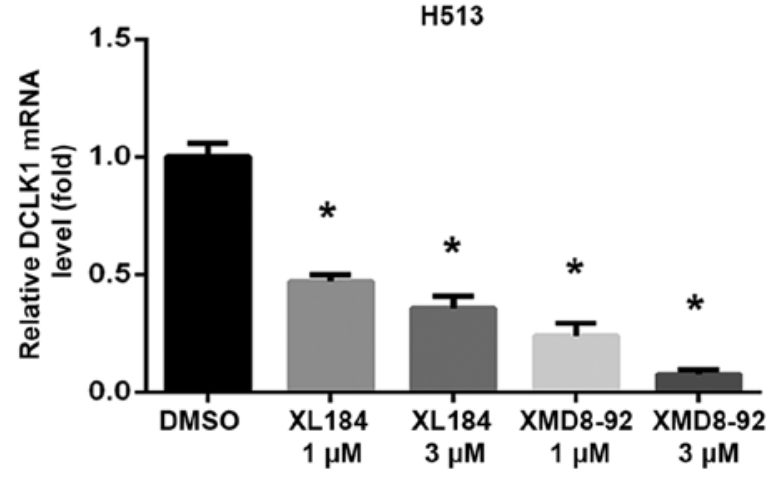

Figure 7. The mRNA level of DCLK1 after MET or ERK5 inhibition in mesothelioma cells. The mRNA level of DCLK1 in (A) H290 and (B) H513 cells treated with MET inhibitor XL184 or ERK5 inhibitor XMD8-92 measured using quantitative real-time PCR ("P<0.0001, one-way ANOVA and Scheffe multiple comparisons).

\section{Discussion}

In our study to evaluate MET, ERK5, and DCLK1 as potential biomarkers and targets for therapeutic development against mesothelioma, we investigated whether MET, or its downstream signaling partners ERK5 and DCLK1, were overexpressed in human mesothelioma cell lines and tissue samples. 
A
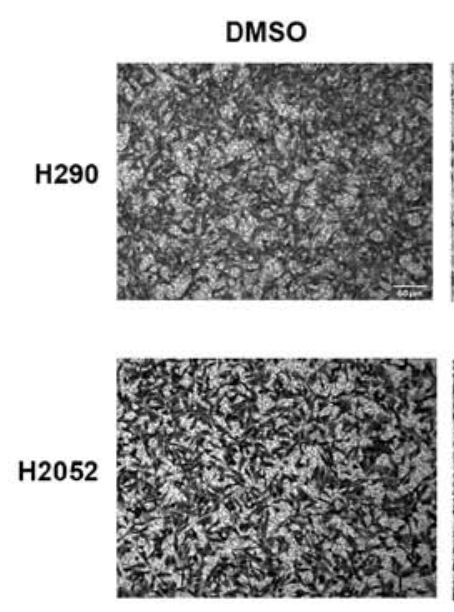

C

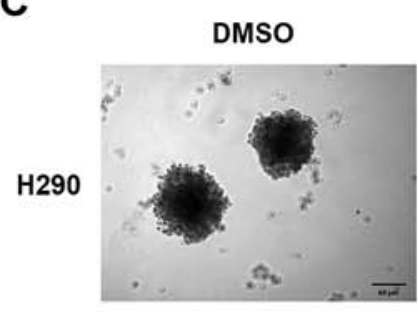

DMSO

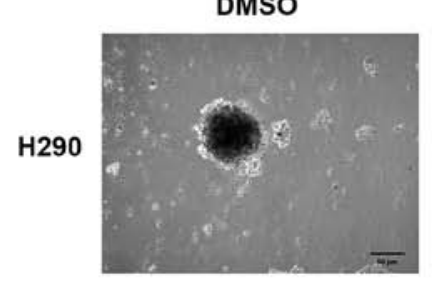

XMD8-92 $1 \mu \mathrm{M}$
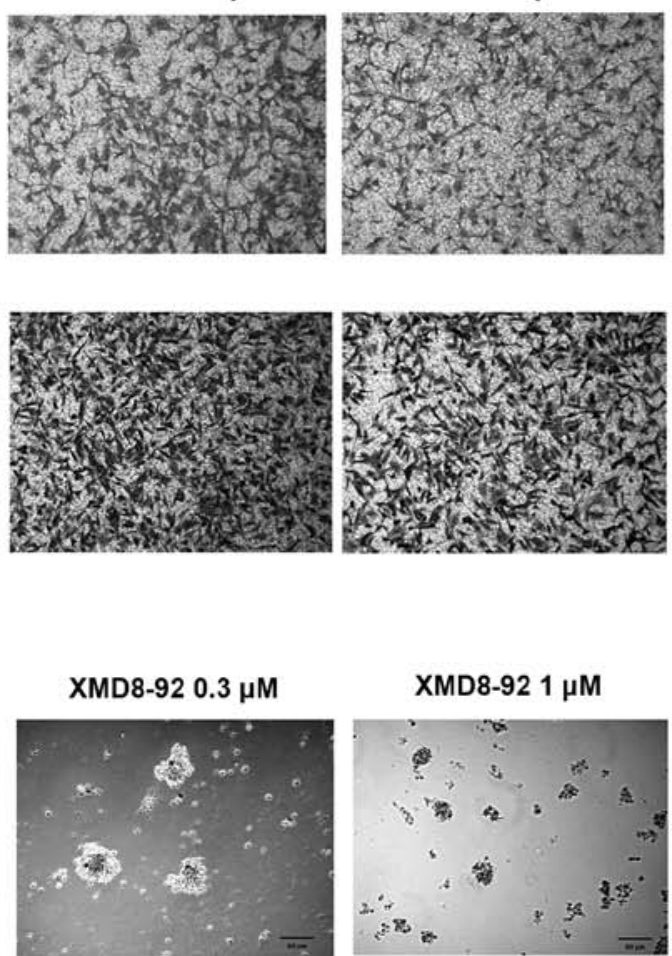

$\mathrm{XL184} 0.3 \mu \mathrm{M}$

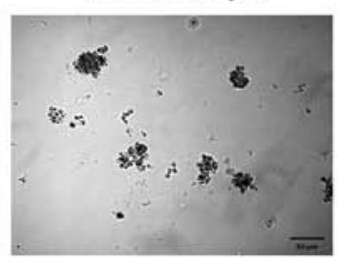

$\mathrm{XL184} 1 \mu \mathrm{M}$

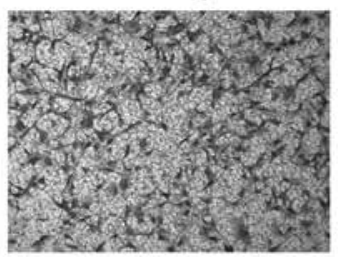

XMD8-92 $1 \mu \mathrm{M}$

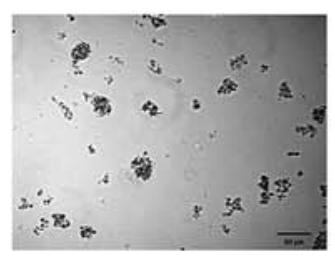

$\mathrm{XL184} 1 \mu \mathrm{M}$

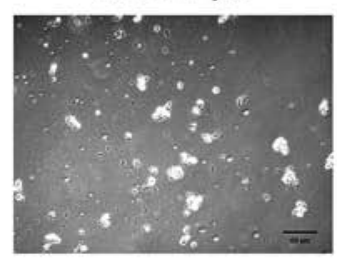

B

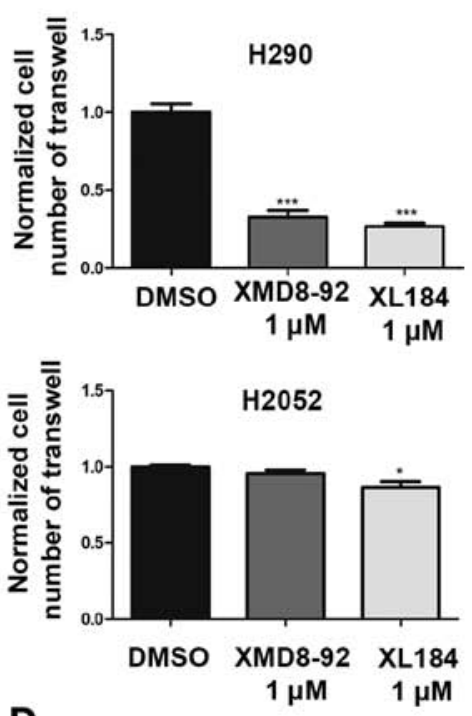

D
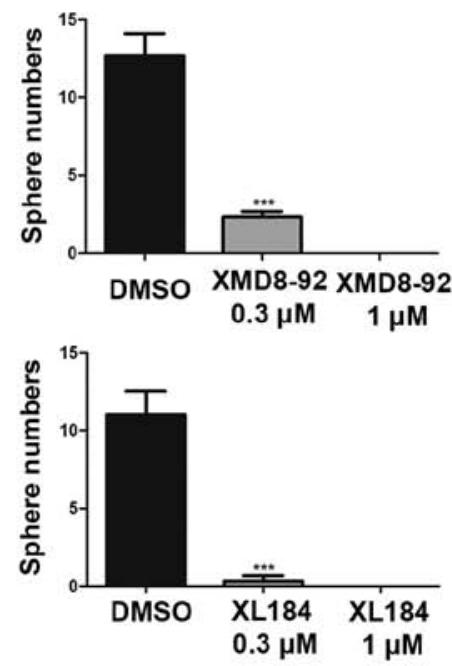

Figure 8. Analysis of cell invasion and tumorsphere formation after XMD8-92 and XL184 in mesothelioma cells. (A) Decrease in cell invasion ability in H290 and $\mathrm{H} 2052$ cells after $1 \mu \mathrm{M}$ XL184 and $1 \mu \mathrm{M}$ XMD3-92 treatment. Images were taken under a 10x objective lens. (B) Quantitative analysis of the number of cells that invaded the lower side of the membrane in each experimental group $\left({ }^{* * *} \mathrm{P}<0.001,{ }^{*} \mathrm{P}<0.05\right.$, one-way ANOVA and Scheffe multiple comparisons). (C) Decrease in sphere formation ability in H290 cells after XMD8-92 and XL184 treatment. Images were taken under a 10x objective lens. (D) Quantitative analysis of tumorsphere assay shows XMD8-92 and XL184 treatment decreased tumorsphere formation ability in H290 cells $\left({ }^{* * * *} \mathrm{P}<0.001\right.$, $\mathrm{P}<0.001$, one-way ANOVA and Scheffe multiple comparisons).

MET amplification has been observed in mesothelioma patients, suggesting that MET is an oncogenic driver and a potential therapeutic target for mesothelioma $(24,25)$. Altered HGF/MET signaling has previously been reported in human mesotheliomas and this pathway plays an important role in tumor invasion and metastasis $(26,27)$. MET receptor activation targets cellular functions involving cell-cell interactions, migration, and remodeling of extracellular matrix. Moreover, paracrine activation of the MET receptor via HGF regulates tumor-stroma interactions. Deregulated activity of MET can lead to many different cancers (28). Our study shows that MET was overexpressed in most of the human mesothelioma samples and it was expressed at low levels in most normal pleural tissues. Furthermore, MET was highly expressed in four $(\mathrm{H} 290, \mathrm{H} 513, \mathrm{H} 28$ and $211 \mathrm{H})$ of six mesothelioma cell lines tested. Negative expression of MET was found in the other two mesothelioma cell lines (MS-1, H2052) and one normal human mesothelial cell line LP9. Different expression of MET in mesothelioma cell lines was also detected by Kawaguchi et al (29). The MET pathway is one of the most frequently dysregulated pathways in human cancer (30). To further analyze the interaction between the MET pathway and cell growth, we used the multi-target MET inhibitor XL184. XL184, which also affects the VEGF receptor 2 (31), and has significant inhibitory activity against numerous solid tumors including melanoma, non-small cell lung cancer, breast cancer, liver cancer, ovarian cancer, and prostate cancer (32-35). The US FDA approved XL184 for the treatment of medullary thyroid cancer in November 2012 (36) and for the treatment of advanced renal cell carcinoma in April 2016 (37). Interestingly, four analyzed human mesothelioma cell lines (H290, H513, $\mathrm{H} 28$ and 211H) which had high expression of MET showed relative high sensitivity $\left(\mathrm{IC}_{50}, \mathrm{H} 290-1.27 \mu \mathrm{M} ; \mathrm{H} 513-1.54 \mu \mathrm{M}\right.$; $\mathrm{H} 28-0.62 \mu \mathrm{M} ; 211 \mathrm{H}-0.46 \mu \mathrm{M})$ to the MET inhibitor XL184. 
XL184 showed only minimal inhibitory effects on the viability of the normal human mesothelial cell line LP9. The prognosis for mesothelioma patients is poor with current surgery and chemotherapy. Our study demonstrated the specific targeting and high sensitivity of XL184 to mesothelioma cells, which indicated that XL184 alone or in combination with other drugs could be worth to performing clinical trials on mesothelioma patients. Furthermore, XL184 significantly inhibited the invasion and tumorsphere formation ability of H290. This supported XL184 may prevent tumor invasion and metastasis. Our data suggested that MET is a potential therapeutic biomarker, and MET inhibitors such as XL184 may be effective therapeutics for patients with mesothelioma. However, in the present study we cannot rule out the possible contributions by the inhibition of other targets of XL184 such as VEGFR2 and RET. Further studies are needed to validate the potential of MET as an effective therapeutic target and XL184 as an effective therapy for patients with malignant mesothelioma in the future.

ERK5 and its upstream kinases enhance cell proliferation, angiogenesis, invasion, and metastasis (38). In a mouse model, ERK5 knockdown increases tumor epithelialization and suppresses intravascular invasion by reducing the generation of circulating tumor cells (CTCs) and the formation of lung metastases in human breast cancer cells (39). ERK5 has also been associated with cancer cell proliferation and survival, and activation by growth factor stimuli $(40,41)$. Studies have shown that HGF promotes proliferation of human mesothelioma cells via ERK5 activation (9). We also observed ERK5 expression in human mesothelioma tumor samples. ERK5 was highly expressed in three cell lines (H290, H513 and H28) of six mesothelioma cell lines. To further investigate the role of the MAPK/ERK pathway, which is important for cancer cell growth and proliferation (42), we used XMD8-92, which is a small molecule inhibitor of ERK5 $(43,44)$. The same three cell lines also showed relative high sensitivity to the ERK5 inhibitor XMD8-92. However, the sensitivity of these cell lines to XMD8-92 is less than the sensitivity to XL184 based on the $\mathrm{IC}_{50}$ of these two inhibitors. Like XL184, XMD8-92 significantly inhibited the invasion and tumorsphere formation ability of H290. Our data suggested that ERK5 may be a potential therapeutic target for patients with mesothelioma.

The role of DCLK1 in cancer has only recently been investigated (45). DCLK1 is overexpressed in several forms of cancer including colon and pancreatic cancer (46). DCLK1 kinase activity may play a critical role in several important pathways involving cell proliferation, cell cycle regulation, epithelial mesenchymal transition (EMT), and stem-cell like properties in cancer (45). DCLK1 is a cancer stem cell (CSC) marker and a potential therapeutic target for pancreatic ductal adenocarcinoma treatment (47), however, its role in human mesotheliomas is unclear. Our study demonstrated that DCLK1 was overexpressed in $47.9 \%$ of the analyzed human mesothelioma tissue samples and was highly expressed in three (H290, $\mathrm{H} 513$ and H28) of the six analyzed mesothelioma cell lines, indicating an important role of DCLK1 in malignant mesothelioma. The statistical analysis of the immunohistochemistry results showed significant association between MET, ERK5 and DCLK1 expression in mesothelioma tissue arrays of the
73 tumor samples. MET, ERK5, and DCLK1 were all highly expressed in three cell lines (H290, H513 and H28) of six mesothelioma cell lines studied. These results suggest that MET, ERK5, and DCLK1 could be closely regulated in human mesothelioma. Moreover, DCLK1 expression was negatively associated with overall survival time of MPM patients, indicating DCLK1 may serve as a predictor for prognosis of MPM patients.

Constitutive activation of ERK5 in various malignant mesothelioma cell lines could be a consequence of activated MET (48). Our results showed that treatment with MET inhibitor XL184 downregulated the protein levels of phospho-ERK5 and DCLK1 (Fig. 6A). After XL184 treatment, the DCLK1 mRNA levels also deceased in a dose-dependent manner (Fig. 7). Regulation of ERK5 expression is important in cancer cells $(49,50)$. The ERK5 inhibitor XMD8-92 can suppress the activity of ERK5 in the vasculature integrity of animals (51) and inhibits DCLK1-mediated kinase activity (44). XMD8-92-mediated DCLK1 inhibition results in suppression of downstream oncogenic signaling, i.e., EMT, angiogenesis, pluripotency, and anti-apoptotic activity (52). We found that XMD8-92 not only decreased the protein levels of phospho-ERK5, but also decreased the protein levels of DCLK1 in mesothelioma cells (Fig. 6B). After XMD8-92 treatment, the DCLK mRNA levels also deceased in a dosedependent manner (Fig. 7). Our results show that this MET/ ERK5/DCLK1 signaling (Fig. 6C) activity could be important for cell growth in mesotheliomas and these small molecule inhibitors could be investigated for their therapeutic potential against mesotheliomas.

In conclusion, we found that MET, ERK5, and DCLK1 are overexpressed in several human mesothelioma cell lines and human mesothelioma tumor tissues. DCLK1 may serve as a predictor for prognosis of MPM patients. Moreover, our results suggest that DCLK1 is regulated by MET/ERK5 signaling in human mesothelioma, and MET and ERK5 could be further developed into a promising therapeutic target against mesothelioma.

\section{Acknowledgements}

This study was supported by the National Institutes of Health (NIH; grant no. R01 CA140654, to L.Y.). We are grateful for support from the Kazan McClain Partners' Foundation. We thank Pamela Derish in the UCSF Department of Surgery for editorial assistance with the manuscript.

\section{References}

1. La Vecchia C and Boffetta P: Role of stopping exposure and recent exposure to asbestos in the risk of mesothelioma. Eur J Cancer Prev.21: 227-230, 2012.

2. Buikhuisen WA, Hiddinga BI, Baas P and van Meerbeeck JP: Second line therapy in malignant pleural mesothelioma: A systematic review. Lung Cancer 89: 223-231, 2015.

3. Mossman BT, Shukla A, Heintz NH, Verschraegen CF, Thomas A and Hassan R: New insights into understanding the mechanisms, pathogenesis, and management of malignant mesotheliomas. Am J Pathol 182: 1065-1077, 2013.

4. Campbell NP and Kindler HL: Update on malignant pleural mesothelioma. Semin Respir Crit Care Med 32: 102-110, 2011.

5. Blume-Jensen $\mathrm{P}$ and Hunter T: Oncogenic kinase signalling. Nature 411: 355-365, 2001. 
6. Maulik G, Shrikhande A, Kijima T, Ma PC, Morrison PT and Salgia R: Role of the hepatocyte growth factor receptor, c-Met, in oncogenesis and potential for therapeutic inhibition. Cytokine Growth Factor Rev 13: 41-59, 2002.

7. Mukohara T, Civiello G, Davis IJ, Taffaro ML, Christensen J, Fisher DE, Johnson BE and Jänne PA: Inhibition of the met receptor in mesothelioma. Clin Cancer Res 11: 8122-8130, 2005.

8. Cacciotti P, Libener R, Betta P, Martini F, Porta C, Procopio A Strizzi L, Penengo L, Tognon M, Mutti L, et al: SV40 replication in human mesothelial cells induces HGF/Met receptor activation: A model for viral-related carcinogenesis of human malignant mesothelioma. Proc Natl Acad Sci USA 98: 12032-12037, 2001.

9. Ramos-Nino ME, Blumen SR, Sabo-Attwood T, Pass H, Carbone M, Testa JR, Altomare DA and Mossman BT: HGF mediates cell proliferation of human mesothelioma cells through a PI3K/MEK5/Fra-1 pathway. Am J Respir Cell Mol Biol 38: 209-217, 2008

10. Regan CP, Li W, Boucher DM, Spatz S, Su MS and Kuida K: Erk5 null mice display multiple extraembryonic vascular and embryonic cardiovascular defects. Proc Natl Acad Sci USA 99: 9248-9253, 2002.

11. Hayashi M, Kim SW, Imanaka-Yoshida K, Yoshida T, Abel ED Eliceiri B, Yang Y, Ulevitch RJ and Lee JD: Targeted deletion of BMK1/ERK5 in adult mice perturbs vascular integrity and leads to endothelial failure. J Clin Invest 113: 1138-1148, 2004.

12. Roberts OL, Holmes K, Müller J, Cross DA and Cross MJ: ERK5 is required for VEGF-mediated survival and tubular morphogenesis of primary human microvascular endothelial cells. J Cell Sci 123: 3189-3200, 2010

13. Rovida E, Spinelli E, Sdelci S, Barbetti V, Morandi A, Giuntoli S and Dello Sbarba P: ERK5/BMK1 is indispensable for optimal colony-stimulating factor 1 (CSF-1)-induced proliferation in macrophages in a Src-dependent fashion. J Immunol 180 4166-4172, 2008.

14. Sureban SM, May R, Lightfoot SA, Hoskins AB, Lerner M, Brackett DJ, Postier RG, Ramanujam R, Mohammed A, Rao CV, et al: DCAMKL-1 regulates epithelial-mesenchymal transition in human pancreatic cells through a miR-200a-dependent mechanism. Cancer Res 71: 2328-2338, 2011.

15. Bailey JM, Alsina J, Rasheed ZA, McAllister FM, Fu YY, Plentz R, Zhang H, Pasricha PJ, Bardeesy N, Matsui W, et al: DCLK1 marks a morphologically distinct subpopulation of cells with stem cell properties in preinvasive pancreatic cancer. Gastroenterology 146: 245-256, 2014.

16. May R, Riehl TE, Hunt C,Sureban SM, Anant S and Houchen CW: Identification of a novel putative gastrointestinal stem cell and adenoma stem cell marker, doublecortin and CaM kinase-like-1, following radiation injury and in adenomatous polyposis coli/ multiple intestinal neoplasia mice. Stem Cells 26: 630-637, 2008.

17. Sureban SM, May R, Qu D, Weygant N, Chandrakesan P, Ali N, Lightfoot SA, Pantazis P, Rao CV, Postier RG, et al: DCLK1 regulates pluripotency and angiogenic factors via microRNAdependent mechanisms in pancreatic cancer. PLoS One 8: e73940,2013.

18. Nakanishi Y, Seno H, Fukuoka A, Ueo T, Yamaga Y, Maruno T, Nakanishi N, Kanda K, Komekado H, Kawada M, et al: Dclk1 distinguishes between tumor and normal stem cells in the intestine. Nat Genet 45: 98-103, 2013

19. Vega KJ, May R, Sureban SM, Lightfoot SA, Qu D, Reed A Weygant N, Ramanujam R, Souza R, Madhoun M, et al: Identification of the putative intestinal stem cell marker doublecortin and CaM kinase-like-1 in Barrett's esophagus and esophageal adenocarcinoma. J Gastroenterol Hepatol 27: 773-780, 2012.

20. Sureban SM, May R, Ramalingam S, Subramaniam D, Natarajan G, Anant S and Houchen CW: Selective blockade of DCAMKL-1 results in tumor growth arrest by a Let-7a MicroRNA-dependent mechanism. Gastroenterology 137: 649-659, 659.e641-642, 2009.

21. Sureban SM, May R, Mondalek FG, Qu D, Ponnurangam S, Pantazis P, Anant S, Ramanujam RP and Houchen CW: Nanoparticle-based delivery of siDCAMKL-1 increases microRNA-144 and inhibits colorectal cancer tumor growth via a Notch-1 dependent mechanism. J Nanobiotechnology 9: 40, 2011.

22. Ali N, Allam H, May R, Sureban SM, Bronze MS, Bader T, Umar S, Anant S and Houchen CW: Hepatitis C virus-induced cancer stem cell-like signatures in cell culture and murine tumor xenografts. J Virol 85: 12292-12303, 2011.

23. Li T, Li H, Wang Y, Harvard C, Tan JL, Au A, Xu Z, Jablons DM and You L: The expression of CXCR4, CXCL12 and CXCR7 in malignant pleural mesothelioma. J Pathol 223: 519-530, 2011
24. Varesano S, Salvi S, Boccardo S, Ravetti JL, Ferro P, Canessa PA, Fedeli F, Pistillo MP and Roncella S: Amplification of MET in a Patient with Malignant Pleural Mesothelioma. J Thorac Oncol 10: e103-e104, 2015

25. Kawakami H, Okamoto I, Okamoto W, Tanizaki J, Nakagawa K and Nishio K: Targeting MET amplification as a new oncogenic driver. Cancers (Basel) 6: 1540-1552, 2014.

26. Matsumoto K and Nakamura T: NK4 (HGF-antagonist/angiogenesis inhibitor) in cancer biology and therapeutics. Cancer Sci 94: 321-327, 2003.

27. Carbone $\mathrm{M}$ and Yang $\mathrm{H}$ : Molecular pathways: targeting mechanisms of asbestos and erionite carcinogenesis in mesothelioma. Clin Cancer Res 18: 598-604, 2012.

28. Davis IJ, McFadden AW, Zhang Y, Coxon A, Burgess TL, Wagner AJ and Fisher DE: Identification of the receptor tyrosine kinase c-Met and its ligand, hepatocyte growth factor, as therapeutic targets in clear cell sarcoma. Cancer Res 70: 639-645, 2010.

29. Kawaguchi K, Murakami H, Taniguchi T, Fujii M, Kawata S, Fukui T, Kondo Y, Osada H, Usami N, Yokoi K, et al: Combined inhibition of MET and EGFR suppresses proliferation of malignant mesothelioma cells. Carcinogenesis 30: 1097-1105, 2009.

30. Liu X, Newton RC and Scherle PA: Developing c-MET pathway inhibitors for cancer therapy: Progress and challenges. Trends Mol Med 16: 37-45, 2010.

31. Yakes FM, Chen J, Tan J, Yamaguchi K, Shi Y, Yu P, Qian F, Chu F, Bentzien F, Cancilla B, et al: Cabozantinib (XL184), a novel MET and VEGFR2 inhibitor, simultaneously suppresses metastasis, angiogenesis, and tumor growth. Mol Cancer Ther 10: 2298-2308, 2011.

32. Trump DL: Commentary on 'Cabozantinib in patients with advanced prostate cancer: results of a phase II randomized discontinuation trial.' Smith DC, Smith MR, Sweeney C, Elfiky AA, Logothetis C, Corn PG, Vogelzang NJ, Small EJ, Harzstark AL, Gordon MS, Vaishampayan UN, Haas NB, Spira AI, Lara PN Jr, Lin CC, Srinivas S, Sella A, SchoffskiSchöffski P, Scheffold C, Weitzman AL, Hussain M, University of Michigan, Ann Arbor, MI.J Clin Oncol 2013;31(4):412-9. doi: 10.1200/JCO.2012.45.0494. Epub 2012 Nov 19. Urol Oncol 31: 1848, 2013.

33. Dai J, Zhang H, Karatsinides A, Keller JM, Kozloff KM, Aftab DT, Schimmoller F and Keller ET: Cabozantinib inhibits prostate cancer growth and prevents tumor-induced bone lesions. Clin Cancer Res 20: 617-630, 2014.

34. Smith DC, Smith MR, Sweeney C, Elfiky AA, Logothetis C, Corn PG, Vogelzang NJ, Small EJ, Harzstark AL, Gordon MS, et al: Cabozantinib in patients with advanced prostate cancer: Results of a phase II randomized discontinuation trial. J Clin Oncol 31: 412-419, 2013.

35. Vaishampayan U: Cabozantinib as a novel therapy for renal cell carcinoma. Curr Oncol Rep 15: 76-82, 2013.

36. Mughal A, Aslam HM, Sheikh A, Khan AM and Saleem S c-Met inhibitors. Infect Agent Cancer 8: 13, 2013.

37. U.S. Food and Drug Administration (FDA): Cabozantinib. CABOMETYX, 2016. https://www.fda.gov/Drugs/Information OnDrugs/ApprovedDrugs/ucm497483.htm.

38. Whyte J, Bergin O, Bianchi A, McNally S and Martin F: Key signalling nodes in mammary gland development and cancer. Mitogen-activated protein kinase signalling in experimental models of breast cancer progression and in mammary gland development. Breast Cancer Res 11: 209, 2009.

39. Javaid S, Zhang J, Smolen GA, Yu M, Wittner BS, Singh A Arora KS, Madden MW, Desai R, Zubrowski MJ, et al: MAPK7 regulates EMT features and modulates the generation of CTCs. Mol Cancer Res 13: 934-943, 2015.

40. Kato Y, Tapping RI, Huang S, Watson MH, Ulevitch RJ and Lee JD: Bmk1/Erk5 is required for cell proliferation induced by epidermal growth factor. Nature 395: 713-716, 1998.

41. Kato Y, Kravchenko VV, Tapping RI, Han J, Ulevitch RJ and Lee JD: BMK1/ERK5 regulates serum-induced early gene expression through transcription factor MEF2C. EMBO J 16: 7054-7066, 1997 .

42. Dhillon AS, Hagan S, Rath O and Kolch W: MAP kinase signalling pathways in cancer. Oncogene 26: 3279-3290, 2007.

43. Deng X, Yang Q, Kwiatkowski N, Sim T, McDermott U, Settleman JE, Lee JD and Gray NS: Discovery of a benzo[e] pyrimido-[5,4-b][1,4]diazepin- $6(11 \mathrm{H})$-one as a potent and selective inhibitor of Big MAP kinase 1. ACS Med Chem Lett 2: 195-200, 2011.

44. Yang Q, Deng X, Lu B, Cameron M, Fearns C, Patricelli MP, Yates JR III, Gray NS and Lee JD: Pharmacological inhibition of BMK1 suppresses tumor growth through promyelocytic leukemia protein. Cancer Cell 18: 258-267, 2010. 
45. Weygant N, Qu D, Berry WL, May R, Chandrakesan P, Owen DB, Sureban SM, Ali N, Janknecht R and Houchen CW: Small molecule kinase inhibitor LRRK2-IN-1 demonstrates potent activity against colorectal and pancreatic cancer through inhibition of doublecortin-like kinase 1. Mol Cancer 13: 103, 2014.

46. Thu KL, Radulovich N, Becker-Santos DD, Pikor LA, Pusic A, Lockwood WW, Lam WL and Tsao MS: SOX15 is a candidate tumor suppressor in pancreatic cancer with a potential role in Wnt/ $\beta$-catenin signaling. Oncogene 33: 279-288, 2014.

47. Qu D, Johnson J, Chandrakesan P, Weygant N, May R, Aiello N, Rhim A, Zhao L, Zheng W, Lightfoot S, et al: Doublecortin-like kinase 1 is elevated serologically in pancreatic ductal adenocarcinoma and widely expressed on circulating tumor cells. PLoS One 10: e0118933, 2015.

48. Shukla A, Miller JM, Cason C, Sayan M, MacPherson MB, Beuschel SL, Hillegass J, Vacek PM, Pass HI and Mossman BT: Extracellular signal-regulated kinase 5: A potential therapeutic target for malignant mesotheliomas. Clin Cancer Res 19: 2071-2083, 2013 .
49. Boguslawski G, McGlynn PW, Harvey KA and Kovala AT: SU1498, an inhibitor of vascular endothelial growth factor receptor 2, causes accumulation of phosphorylated ERK kinases and inhibits their activity in vivo and in vitro. J Biol Chem 279: 5716-5724, 2004.

50. McCubrey JA, Steelman LS, Chappell WH, Abrams SL, Wong EW, Chang F, Lehmann B, Terrian DM, Milella M, Tafuri A, et al: Roles of the Raf/MEK/ERK pathway in cell growth, malignant transformation and drug resistance. Biochim Biophys Acta 1773: 1263-1284, 2007.

51. Yang Q and Lee JD: Targeting the BMK1 MAP kinase pathway in cancer therapy. Clin Cancer Res 17: 3527-3532, 2011.

52. Sureban SM, May R, Weygant N, Qu D, Chandrakesan P, Bannerman-Menson E, Ali N, Pantazis P, Westphalen CB, Wang TC, et al: XMD8-92 inhibits pancreatic tumor xenograft growth via a DCLK1-dependent mechanism. Cancer Lett 351: 151-161, 2014. 